\section{OPEN ACCESS}

\title{
Enhancing active living and physical exercise through environmentally friendly policies in urban areas \\ Enhancing active living and physical exercise through environtentally fiendly policies in urban areas
}

\author{
Authors' contribution: \\ A) conception and design \\ of the study \\ B) acquisition of data \\ C) analysis and interpretation \\ of data \\ D) manuscript preparation \\ E) obtaining funding
}

Received: 10.08 .2020

Accepted: 26.07 .2021

\author{
Charilaos Kouthouris ${ }^{1 \mathrm{~A}-\mathrm{D}}$ (D), Aglaia Zafeiroudi ${ }^{1 \mathrm{~A}-\mathrm{C}}$ (D), \\ Sotirios Georgomanos ${ }^{2 \mathrm{~B}}$, Evangelia Kontogianni ${ }^{1 \mathrm{~B}}$ \\ ${ }^{1}$ University of Thessaly, Trikala, Greece \\ ${ }^{2}$ Aristotle University of Thessaloniki, Thessaloniki, Greece
}

*Correspondence: Charilaos Kouthouris, Dep. Physical Education \& Sport Science, University of Thessaly, Greece, Karies, Trikala, 42100, E-mail: kouthouris@uth.gr

\begin{abstract}
Active living offers a substantial contribution to the mental and physical health of individuals, as well as to community wellbeing and social cohesion. Outdoor and green environments offer additional benefits and determine people's involvement in physical exercise. Environmental policies put in place by local governments affect citizens' adoption of active living and physical exercise. The aim of the present study was to investigate the relationship between citizens' levels of exercise participation in urban open spaces and the provision of exercise-friendly policies by the local authorities. Three hundred and seventy citizens participated in the present study who took part in walking, bicycling, or jogging/ running during their leisure time in urban open spaces and outdoors. Research participants completed the Godin LeisureTime Exercise Questionnaire (GLTEQ; Shephard, 1997) and Environmentally Friendly Exercise Policy Questionnaire (Kontogianni, 2015), which consisted of three scales: "policy to enhance exercise," "environmentally friendly exercise facilities," and "intention to change personal habits." Participants were divided into three different subgroups according to their time exercise scores: high, middle, and low. The results showed the statistically significant differences between time exercise scores and environmentally friendly exercise policy scales. Citizens with higher exercise time participation expressed significantly higher levels on the environmentally friendly exercise policy scales. Citizens' physical exercise time in urban open spaces and outdoors seemed to affect the creation of corresponding preferences, beliefs, and intentions towards environmentally friendly policies. City leaders, essential decision-makers, and stakeholders are expected to provide an enabling environment, legitimacy, and leadership that fosters the development and implementation of policies that support physical activity and green active living within urban spaces.
\end{abstract}

Keywords: Leisure, outdoor recreation, health, wellbeing, green public facilities

\section{Introduction}

Physical inactivity has been a problem in recent years as a significant number of citizens are at risk for noncommunicable diseases such as hypertension, diabetes, and obesity. Globally, $23 \%$ of adults and $81 \%$ of adolescents (aged 11-17 years old) do not meet the WHO global recommendations on physical activity for health. Inactivity varies within and between countries and can be as high as $80 \%$ in some adult subpopulations (World Health Organization, 2020). In addition, physical inactivity affects psychological impairment, resulting in depression 
and anxiety (Mayo Clinic Staff, 2017). The promotion of physical exercise has been a subject of multiple action plans by various governments in different urban areas globally. Saito et al. (2018) conducted research among 3,000 community-based adults (aged $\geq 20$ years old), and Cheung, Talley, McMahon, Schorr, and Wyman (2020) investigated 434 participants with a mean age of 65 years. Both posited that most adults do not meet the healthrelated guidelines for physical activity, which leads to inactivity being considered as a central global problem. There is an urgent need to conceptualize participation in physical activity on a population basis since intervening in small groups or on the individual level brings about minimal change to the community. Environmental policy and interventions promise to promote physical activity since they are fundamentally designed to influence large groups, even entire populations, according to Panter, Guell, Prins, and Ogilvie (2017). Mengesha, Roba, Ayele, and Beyene (2019) believe that the rhetoric used to promote exercise and a healthy lifestyle has for a long time endorsed the value of the policy and environmental interventions in that direction. Several interventions thus far have been introduced to promote physical activity in urban areas (Camhi et al., 2019). Most of these responses focus on specific activities (e.g., cycling and walking) as well as diverse contexts such as parks, fields, forests, squares, streets, and urban open spaces. Furthermore, most of these interventions address health concerns by tackling barriers in the existing physical and social systems that are responsible for generating and sustaining inactivity to promote physical exercise. Moreover, environmental approaches may include but are not limited to constructing cycling and walking routes and developing green spaces that are more adequate for active recreation. Most of these interventions are heterogeneous in their context, delivery, and content. Thus, they are implemented by different practitioners and policymakers within the urban environment. Despite the efforts made thus far, the problem of inactivity among urban citizens still remains.

Research has shown that people prefer to exercise outdoors as they find it to be more enjoyable, it gives them greater satisfaction, and it promotes their intention to continue exercising in the future (Wagner, Keusch, Yan, \& Clarke, 2019). Contact with the natural environment and interaction with other humans seems to play a key role in these feelings. Environmental pollution seems to act as a barrier to participating in exercise outdoors (such as running, cycling, and walking), especially in urban places (Madureira, Brancher, Costa, Pinho, \& Teixeira, 2019). Environmental pollution, especially air pollution, impacts outdoor exercise and causes many health problems (Hu, Zhu, Xu, Lyu, Imm, \& Yang, 2017).

The present research came from a broader reflection on facilitating citizens' participation in physical exercise in a healthier and greener urban space. In order to improve the conditions for citizens' participation in activities in an urban area, it is important to take into account their needs and wishes. This research analyzes the needs of physically active citizens in urban open green spaces according to their physical activity in order to provide information and green policies to maximize their quality of life.

More specifically, this research paper evaluates the need for environmental and policy interventions while examining the relationship between physical exercise among citizens and the enactment of environmentally friendly policies. The present study attempts to collect data from citizens who exercise during their leisure time in urban open spaces and parks to create a convenient environment for exercise through green policies. The potential result could be the development of a sustainable public policy to enhance active living, reduce the proportion of inactive citizens, and facilitate exercise.

\section{Literature review}

For the first time in history, there are more citizens residing in urban areas than rural settlements (Johnson \& Shifferd, 2016; Tan et al., 2017). Johnson and Shifferd (2016) note that urban areas provide more benefits in the areas of access to social, educational, and health services, cultural resources, and a lively community. However, Zhang, Cao, and Ramaswami (2016) list several urban centers that are associated with compromised opportunities. Moreover, social and physical environments largely determine the state of individual health. As such, the subject of urban and public health becomes one that arouses concerns from different professionals affiliated with catering to the wellness of populations. Most importantly, urban health encompasses wide-ranging issues, from food quality to substance abuse, violent crime, social cohesiveness, and mental health.

Physical activity is a crucial aspect in any strategy aiming to address the concerns and predicaments associated with obesity and sedentary living among both adults and children in urban centers. Active living is known to offer a substantial contribution to the mental and physical wellbeing of individuals, as well as to community wellbeing and social cohesion. Moreover, opportunities for physical exercise are not only limited to organized recreation and sporting activities, but actually exist everywhere: in leisure, health, and educational establishments, in diverse neighborhoods, and where people work and live. Adequate spaces for physical exercise in cities 
include parks, recreation areas, sports centers, roads, urban forest paths, artificial lakes, playgrounds, and other spaces. These urban ground spaces that are not roofed by an architectural structure are defined as urban open spaces (Stanley, Stark, Johnston, \& Smith, 2013). The kinds of physical activities practiced in these areas include but are not limited to jogging, bicycling, running, walking, and individual or group sports such as football, volleyball, golf, and tennis.

\section{Benefits of physical exercise and a green exercise environment}

Hopkins, Gibbons, and King (2018) note that physical exercise aids in controlling individual body weight. Moholdt, Lavie, and Nauman (2018) highlight that physical activities reduce the risk of contracting high blood pressure and other heart diseases such as heart attack and coronary artery disease. In addition, physical activities help the body manage high levels of insulin and blood sugar, lowering the risk of contracting type 2 diabetes and metabolic syndrome. Moreover, physical exercise reduces withdrawal symptoms and cravings for cigarettes. In urban environments, physical activities reduce the risk of cancer. Finally, physical exercise improves sleeping patterns by helping people in urban environments fall asleep within the shortest possible time and stay asleep for longer.

Furthermore, physical exercise offers several psychological benefits. For example, physical activities improve the mental mood and health of people in urban areas, helping them deal with depression and anxiety (Aguiñaga et al., 2018). Physical exercise also reduces the stress levels of participants, leading to higher levels of happiness and increased self-confidence and self-esteem. Additionally, physical exercise improves individual judgment, learning, and thinking skills, sharpening them as one ages. In this case, Schüller and Demetriou (2018) prove that physical exercise boosts intelligence and strengthens individual memory. Overall, there is no shortage of benefits tied to physical activity for citizens in urban spaces.

These studies support the argument that physical activity improves both physiological and psychological wellbeing, but different environments also play an important role in health. Outdoor, environmentally friendly areas motivate and facilitate physical activity (Zafeiroudi, 2020; Zafeiroudi \& Hatzigeorgiadis, 2014b). Additional health benefits, revitalization, and further engagement in an active lifestyle occurs when exercise is performed in outdoor and green environments (Bamberg, Hitchings, \& Latham, 2018; Gladwell, Brown, Wood, Sandercock, \& Barton, 2013). The combination of physical exercise and exposure to healthy green environments could be used to combat inactivity and disease.

Rapid urbanization has changed city surfaces and caused many problems in the natural environment, resulting in the reduction of green spaces (Li, Zheng, Wang, Liang, Xie, Guo, Li, \& Yu, 2019; Zhou \& Wang, 2011). Many local governments have realized the important role of physical exercise and green space in urban facilities and have adopted a series of policies to introduce green elements into urban areas. Environmentally friendly policies seem to be essential for guiding sustainable physical exercise, active lifestyles, and green development (Kontogianni, Zafeiroudi, \& Kouthouris, 2020; Kontogianni, Kouthouris, \& Zafeiroudi, 2014).

\section{Environmental policies and physical exercise in urban areas}

The way cities are designed provides access to the surrounding citizens within urban spaces. Sallis et al. (2016) highlight that such a design can be a great hindrance or encouragement to active living and physical exercise. Several barriers exist within the social environment in which people live, play, and work. Most importantly, people suffering from chronic diseases and obesity are socially disadvantaged, and most endure the unforgiving consequences of poverty. As such, it becomes imperative to address the contributions and needs of all citizens in their daily lives through general and specific policies to promote active living and physical activity.

Kostrzewska (2017) believes that local governments have shown tremendous support in promoting physical activity through their influence on the built environment and other mechanisms. In this case, local governments, particularly in cities across the globe, have introduced several decisions on the design and planning of street locations, layouts, and land use policies, which include specifications for allowable street widths and sidewalks. A survey included data on 6,919 adults from Angers (France), Bonn (Germany), Bratislava (Slovakia), Budapest (Hungary), Ferreira do Alentejo (Portugal), Forlì (Italy), Geneva (Switzerland), and Vilnius (Lithuania) who were contacted by researchers (Ellaway, Macintyre, \& Bonnefoy, 2005). The results showed that more greenery and less litter in residential environments were associated with increased participation in physical exercise and better health. The United States of America, the United Kingdom, Australia, and Europe have adopted and promoted green policies in cities to encourage physical exercise outdoors such as active transportation, planting trees and flowers in city squares, and providing access to forests, rivers, and lakes on the periphery of cities (Edwards \& Tsouros, 2006). 
Local governments own and are charged with maintaining neighborhood playgrounds and parks (Livy \& Klaiber, 2016). Furthermore, they also operate and are expected to sustain different sporting and recreational facilities. Chen, Jiao, $\mathrm{Xu}, \mathrm{Gao}$, and Bischak (2018) posit that multiple cities are working together with school districts in promoting bicycling and walking through school programs and other initiatives. More extensive efforts that aid in improving traffic laws and enforce traffic safety encourage children to play, cycle, and walk. Such programs enable school-going children to take advantage of the appropriately shaped environment to engage in physical exercise. In addition, the general policies, action plans, and strategies of local governments aim to encourage physical activity in urban spaces, decrease the prevalence of sedentary lifestyles, and raise awareness of the need for and importance of active living and physical activity (Pawlikowska-Piechotkaanna \& Sawicka, 2013).

For each of the identified general goals and policies, there are different action plans provided for implementation. For example, to encourage physical activity, local governments in the USA, Canada, and some European countries encourage bicycling and walking for recreation and transportation by improving the built environment (Winters, Buehler, \& Götschi, 2017). In this case, local governments are collaborating with developers and school districts to create new learning institutions in locations close to residential areas and far from roads that are heavily trafficked. Futhermore, Panter, Heinen, Mackett, and Ogilvie (2016) note that the number of destinations within bicycling and walking distance are being increased. Moreover, there are numerous plans to build and maintain wellconnected networks of paths and off-street trails for bicyclists and pedestrians.

Other local governments are working on expanding trail and path networks. Still others are adopting community policing strategies geared towards improving the security and safety of streets, especially for neighborhoods prone to high rates of criminal activity. In addition, policies are in place to foster routine physical activity by instituting various regulatory policies that mandate a minimum space for playing, duration of play, and physical equipment for childcare programs. Different workplace practices and policies are also being instituted to foster exercise breaks and other physical activities.

Several policies are being instituted to decrease sedentary lifestyles as well. For example, Kabisch and Kraemer (2020) note that local governments are adopting action steps and regulatory policies to enhance exercise for vulnerable groups. Furthermore, various measures have been implemented by local, state, and national governments to raise awareness of the need for and importance of increasing and advancing active living and physical activities within the urban environment. Moreover, social media marketing strategies and campaigns have been adopted to emphasize the benefits of physical activity to the masses. Media campaigns using promotional materials, the internet, radio, television, and print media have been instrumental in promoting the adoption of exercise. In addition, different counter-advertisements are in place against sedentary living to reach out to children and adults.

Overall, environmental policies put in place by local governments significantly affect the adoption of active living and physical exercise among citizens. As local governments continue to cooperate with and involve other stakeholders, more opportunities are available for citizens to participate in physical activity. Moreover, the natural, social, and built environment determines individuals' involvement in physical exercise.

As the concern about active exercise is becoming increasingly significant in the sustainable society, individuals are moving towards more environmentally friendly policies and exercise facilities. Limited research has been undertaken to understand citizens' perception of environmentally friendly attitudes and behavior, and little is known about the relationships between exercise and environmental policy. Considering the lack of research, the present study aims to investigate citizens' preferences for a positive, environmentally friendly exercise policy in the context of urban open spaces. Specifically, the research hypothesis of the study questions whether citizens who are more involved in physical exercise in urban open spaces express higher desires for exercise-friendly policies and an ecological approach to the management of recreational facilities through their intention to change their personal habits.

\section{Method}

\section{Participants and procedure}

Four hundred and fifty questionnaires were distributed in urban open municipal recreational spaces and parks. Three hundred and seventy were returned, for a response rate of $85.6 \%$. Participants completed the questionnaires using a pencil and paper in the presence of the researchers. Participants exercised frequently by walking, bicycling, or jogging/running in outdoor urban areas such as sidewalks, cycle roads, municipal parks, and forests. The demographic characteristics of the sample are presented in Table 1. 
Table 1. Demographic data of the sample

\begin{tabular}{cccc}
\hline Exercise activity & Marital status & Age subgroups & Educational level \\
\hline Running: & Single: 202 & $1^{\text {st }}$ group $(18-28):$ & Primary education: \\
$79(21.4 \%)$ & $(54.6 \%)$ & $107(28.9 \%)$ & $118(31.9 \%)$ \\
Bicycling: & Married: 168 & $2^{\text {nd }}$ group $(29-38):$ & Secondary education: \\
$126(34.1 \%)$ & $(45.4 \%)$ & $128(34.6 \%)$ & $162(43.8 \%)$ \\
Walking: & & $3^{\text {rd }}$ group $(39<):$ & University graduates: \\
$165(44.6 \%)$ & & $135(36.5 \%)$ & $90(24.3 \%)$ \\
\hline
\end{tabular}

\section{Research instruments}

\section{Exercise Time Participation Questionnaire}

Exercise time participation was self-reported using the Godin Leisure-Time Exercise Questionnaire (GLTEQ; Godin \& Shephard, 1997). Participants were asked to indicate how many times on average during a typical 7-day period (a week) they engaged in specific kinds of physical activity (e.g., strenuous: running/jogging; moderate: cycling/fast walking; light: walking) for more than 15 min during their free time in urban open spaces and outdoors. Weekly frequencies of vigorous, moderate, and light activities were multiplied by nine, five, and three METS (units of metabolic equivalence), respectively. The total weekly leisure activity was calculated by summing the products of the separate components: weekly leisure activity score $=(9 \times$ Strenuous $)+(5 \times$ Moderate $)+(3 \times$ Light $)$.

\section{Environmentally Friendly Exercise Policy Questionnaire}

Environmentally friendly exercise policy indicates a dynamic policy to cover citizens' preferences and needs in the area of convenient participation in physical exercise in urban open spaces and outdoors. The questionnaire was expressed by the following three scales:

i) The first scale, called "policy to enhance exercise," expressed citizens' expectations for a positive and active living policy in urban areas by local authorities. This scale aimed to assess citizens' preferences toward the development of a public policy that would enhance their exercise participation in outdoor and urban open spaces such as sidewalks, parks, and squares. The scale consisted of five items (e.g., "The promotion of a policy that will encourage citizens to do exercise in open spaces and outdoors is very important."). Two items were negatively worded (e.g., "Under the current economic crisis, I believe that spending money for active leisure infrastructure and creating opportunities for open space and outdoor exercise is not useful to citizens."). Answers were given on a 7-point Likert scale (from $1=$ very strongly disagree to $7=$ very strongly agree).

ii) The second scale, called "environmentally friendly exercise facilities," encouraged local authorities to use an eco-management approach in the construction of sports or recreational facilities. The scale consisted of five items (e.g., "The public should use alternative energy sources in urban sports areas such as wind or solar."). Answers were given on a 7 -point Likert scale (from $1=$ very strongly disagree to 7 = very strongly agree).

iii) The third scale, called "intention to change personal habits," expressed citizens' willingness to change their daily habits and adopt more green behaviors. The scale consisted of five items (e.g., "I am willing to "confine my comfort' or 'change personal everyday habits."). Answers were given on a 5-point Likert scale (from $1=$ strongly disagree to $5=$ strongly agree). The three scales were tested successfully (Kontogianni, 2015).

\section{Results}

\section{Exercise time participation}

Participants were separated into three groups according to their exercise score achievements. The first group consisted of 72 individuals (19.5\%) who accumulated 9-23 units (METs) per week and were classified as low-rate exercisers. The second group consisted of 72 individuals (19.5\%) who accumulated 24-53 units (METs) per week and were classified as middle-rate exercisers. Finally, the third group consisted of $226(61 \%)$ individuals who accumulated 54-119 units (METs) per week and were classified as high-rate exercisers. 


\section{Descriptive statistics and correlations}

According to the three "environmentally friendly exercise policy" scales, participants reported the highest score for "policy to enhance exercise" $(\mathrm{M}=6.01, \mathrm{SD}=.93)$ and relatively high scores for "environmentally friendly exercise facilities" $(\mathrm{M}=5.18, \mathrm{SD}=1.04)$ and "intention to change personal habits" $(\mathrm{M}=4.36, \mathrm{SD}=.69$; Table 2$)$.

Table 2. Descriptive statistics

\begin{tabular}{lcccccc}
\hline Scales & N-items & Min & Max & M & SD & Coefficient $\alpha$ \\
\hline Policy & 5 & 1 & 7 & 6.01 & 0.93 & .84 \\
Facility & 5 & 1 & 7 & 5.18 & 1.04 & .92 \\
Intention & 5 & 1 & 5 & 4.36 & 0.69 & .94 \\
\hline
\end{tabular}

A bivariate Pearson's correlation analysis tested the relationships between the three "environmentally friendly exercise policy" scales. The results indicated strong relationships between all the scales. "Policy to enhance exercise" showed the highest correlation with "environmentally friendly exercise facilities" $(\mathrm{r}=.578, \mathrm{p}<.01)$, followed by "intention to change personal habits" $(\mathrm{r}=.516, \mathrm{p}<.01)$. The remaining correlations between "policy to enhance exercise" and "intention to change personal habits" were also significant $(\mathrm{r}=.458, \mathrm{p}<.01)$.

\section{Differences between exercise time and "environmentally friendly exercise policy"}

An analysis of variance was conducted to test for differences between the "environmentally friendly exercise policy" scales as the three dependent variables and exercise time (low, middle, high) as the independent variable. The analysis revealed significant effects for "policy" $\left(\mathrm{F}_{(2,367)}=5.01, p<.01\right)$, "facilities" $\left(\mathrm{F}_{(2,367)}=4.21, p<.01\right)$, and "intention" $\left(\mathrm{F}_{(2,367)}=9.93, p<.001\right)$. Post-hoc analysis (Sheaffe's) revealed that the high exercise time subgroup scored significantly higher than the middle and low exercise time subgroups in all scales. The ANOVA scores are presented in Table 3.

Table 3. Analysis of "Environmentally Friendly Exercise Policy" scales and exercise time

\begin{tabular}{lccc}
\hline Exercise Time & Policy & Facilities & Intention \\
\hline & $\mathrm{M}( \pm \mathrm{SD})$ & $\mathrm{M}( \pm \mathrm{SD})$ & $\mathrm{M}( \pm \mathrm{SD})$ \\
\hline $1^{\text {st }}$ group (low) & $5.84( \pm 1.25)$ & $4.15( \pm 0.89)$ & $4.63( \pm 1.10)$ \\
$2^{\text {nd }}$ group (middle) & $6.17( \pm 0.81)$ & $4.39( \pm 0.58)$ & $5.25( \pm 0.91)$ \\
$3^{\text {rd }}$ group (high) & $6.24( \pm 0.84)$ & $4.42( \pm 0.65)$ & $5.30( \pm 1.01)$ \\
& $\mathrm{F}=5.01, \mathrm{p}<.01$ & $\mathrm{~F}=4.21, \mathrm{p}<.01$ & $\mathrm{~F}=9.93, \mathrm{p}<.001$ \\
& $1-3^{*}$ & $1-3^{*}$ & $1-2 / 3^{* *}$ \\
\hline
\end{tabular}

Note. ${ }^{*} \mathrm{p}<.05, * * \mathrm{p}<.01$

\section{Discussion}

The results of the present study highlight an important issue concerning the quality of life and wellbeing of citizens in urban places. For citizens to live sustainably in urban places, there must be a serious reduction in environmental pollution and conditions that cause inactivity as well as a promotion of conditions that encourage health-promoting actions. Improving the conditions for a healthy environment and strengthening the construction of leisure and sports facilities remains central to the mission of public administrations. Any new strategy could have a greater chance of success and better results if it takes into account the suggestions and wishes of citizens.

The present research came from a broader reflection on how citizens can be motivated to participate in exercise through the greening of the outdoors. Recent researchers have suggested that greening urban areas correlates to increased physical activity and promotes wellbeing (Jin, Kwon, Yoo, Yim, \& Han, 2021; Tan et al., 2021; Schipperijn, Bentsen, Troelsen, Toftager, \& Stigsdotter, 2013). Other studies have focused on the investigation of health 
benefits and physical exercise levels and comparing urban facilities through policy interventions focusing again on health benefits. A gap was found in the investigation of urban citizens' opinions about urban open spaces. In order to improve the conditions for citizen participation in activities in urban open spaces, it is important to take into account the needs and wishes of the citizens.

The desire of the citizens to configure urban open spaces for physical activity was recorded, sending a promising message to public authorities. The survey data was collected by citizens who dedicate a significant part of their free time during the week to supporting their health through exercise. The analysis of the data sends a clear message to improve the urban environment. This message highlights the conditions that citizens want to experience in this endeavor.

The questionnaires used in this study were the Godin Leisure-Time Exercise Questionnaire (GLTEQ; Godin \& Shephard, 1997) and the Environmentally Friendly Exercise Policy Questionnaire (Kontogianni, Kouthouris, \& Zafeiroudi, 2014). The GLTEQ was used as it classifies respondents into active and insufficiently active groups. It provides evidence about physical activity, environmental factors, and policies (Tuyckom, 2011). The existing studies have focused mainly on health and the availability and quality of urban open space and recreational facilities. Tuyckom (2011) also mentioned that the link between policy and physical activity levels requires further investigation. Some studies have focused on the associations between environmental and leisure time physical activities (Pyky, Neuvonen, Kangas, Ojala, Lanki, Borodulin, \& Tyrvainen, 2019; Rech, Reis, Hino, \& Hallal, 2014). The results of the present research confirmed the findings of the previous studies, showing the relationship between physical activity and environmental factors. In addition, the present research added value by showing physically active citizens' opinions about environmental change through policies and strategies. The Environmentally Friendly Exercise Policy Questionnaire consisted of the three following scales: "policy to enhance exercise," "environmentally friendly exercise facilities," and "intention to change personal habits." The items of the three scales were adopted to the new research concept as they were used in previous research (Kontogianni, Kouthouris, \& Zafeiroudi, 2014) investigating the environmentally friendly behavior of participants in leisure and recreational activities.

According to the results, the main objective of the study was supported. As such, citizens who regularly exercise in urban spaces express significantly higher levels of environmental care through friendlier policies. When analyzing demographics, there were no differences in exercise participation between men and women, age groups, and different marital statuses. The type of physical activity that is preferred mostly by citizens in their free time is intense walking, followed by cycling and jogging/running. Walking is the most popular physical exercise as it does not require significant equipment, allows for fluctuations from low to high intensity, and can be done individually or with others. Walking does not cause injuries to participants and is recommended by doctors as an activity for prevention or rehabilitation.

The participants were divided into three distinct low, middle, and high groups according to their participation in the above forms of exercise, and there was an equal distribution of the population in each group. It is also important to note the internal consistency of the Environmentally Friendly Exercise Policy Questionnaire, as high correlations were found between all three scales, "policy to enhance exercise," "environmentally friendly exercise facilities," and "intention to change personal habits."

The most important result of the research, which confirmed the basic hypothesis, was the finding of significant differences between all exercise groups and the scores achieved in all three scales of the Environmentally Friendly Exercise Policy Questionnaire. These results helped the researchers argue in a more accurate way that differences between the exercise time groups corresponded to their needs and desires for environmentally friendly policies.

Inactivity is detrimental to the mental and physical health of citizens. Addressing this problem necessitates the introduction of policies that favor and promote physical activity. Thus, local governments have an imperative role in reducing the current trends of physical inactivity in cities and urban environments. Most importantly, approaches that have been adopted to change individual behavior show little to no success. As such, practices and policies that enable urban residents to be physically active have a higher likelihood of success when they modify the immediate social and physical environment.

Environmentally friendly exercise policy was the central issue of the study. In particular, the highest scores appeared with "policy to enhance exercise," followed by "environmentally friendly exercise facilities." Citizens know that mainly political power held by the government or the local authorities is required to change legislation or laws. Scores for the third scale, "intention to change personal habits," were also high, revealing the intention of the citizens to support environmentally friendly policies through their individual contribution. In addition, these positive correlations support the cohesiveness and validity of the "environmentally friendly exercise policy" variable as a central issue in the study. 
Furthermore, according to the analysis of variance, statistically significant differences were found between time participation scores and the three "environmentally friendly exercise policy" scales. It is remarkable that the scores gradually decreased on all three scales. These results suggest that despite the exercise time participation of each group, the demand for a more environmentally friendly exercise policy remains high.

As such, in the long run, policy changes at the state, regional, and national levels seem to be imperative in encouraging increased active living and participation in physical activity by making these choices more comfortable. For example, when vehicular traffic speed is reduced and provisions are made for safer walking and cycling routes, there can be an advancement in the physical activity of city residents, which ultimately results in a reduction of and better prevention against non-communicable diseases (Andrade et al., 2018; Breda et al., 2018). Moreover, when land use is mixed within urban spaces, people are more likely to walk to schools, shops, workplaces, and other destinations. Each kilometer walked per day contributes to overall individual physical activity.

There are also various determinants of active living and physical activity in the urban environment. These individual determinants include but are not limited to disability and ability, motivation, attitudes, beliefs, skill level, age, and sex. According to the literature review, the key barriers that prevent citizens from engaging in meaningful exercise include the lack of or problems with accessing sporting and recreation facilities, pollution and transport emissions, fears concerning road safety and crime, and negative attitudes toward active transport and physical activity. As such, addressing these challenges is crucial to engaging more of the urban population in physical activity. For example, if citizens believe that cycling is a dangerous endeavor, they will not appreciate or participate in it. On the other hand, the underlying reasons behind citizens' active lifestyles and participation in physical activity are an expected array of benefits, enjoyment purposes, and self-efficacy.

Moreover, the urban social environment is inclusive of diverse dimensions that influence individual participation in physical activities, such as equity and socioeconomic status. Notably, the socioeconomic status of city residents is inversely related to their involvement in leisure activities (Biernat \& Buchholtz, 2016; Sugiyama, Howard, Paquet, Coffee, Taylor, \& Daniel, 2015). In this case, people from low-income homes and families have low leisure and discretionary time and inhibited access to facilities offering greener spaces and exercise. On the other hand, the cultural beliefs of urban people also influence their activity and determine which physical exercises they believe are considered appropriate for people from different groups, ages, and sexes (Hesketh, Lakshman, \& van Sluijs, 2017).

Governments at national, regional, and local levels are challenged by the increasing frequency of sedentary lifestyles, obesity, and the prevalence of chronic ailments. Physical inactivity in urban spaces is the most significant contribution to these problems. Consequently, physical activity promises a multitude of benefits for the physical and mental wellbeing of urban residents. In addition, active living and outdoor physical activity are specifically crucial to the health advancement of young people and children (Zafeiroudi \& Hatzigeorgiadis, 2014b). Moreover, active aging introduces a dramatic difference in older people's wellbeing. Furthermore, active living and physical exercise also contribute significantly to social cohesion and economic prosperity in cities. Consequently, taking part in physical activity increases diverse opportunities for cultural identity, networking, and socialization.

However, the promotion of active living and physical activity in urban environments requires the cooperation and involvement of all levels of governance, including local, regional, and national levels, with apparently clear commitments and roles for each level. In this case, local governments play a crucial role in creating urban spaces, opportunities, and environments for active living and physical activity. City leaders, other essential decision-makers, and stakeholders are expected to provide an enabling environment, legitimacy, and leadership that fosters the development and implementation of policies supporting physical activity and active living within urban spaces.

On the other hand, public institutions ought to promote more opportunities for exercise and active leisure participation for all citizens. Public policy could increase the environmental responsibility of society and, consequently, citizens' quality of life. The involvement of city residents in physical activity is significantly influenced by the natural and built environment in which they reside, personal factors (motivation, ability, age, and gender), and their social environment. As such, design elements within the city environment such as the location of public buildings, parks, and recreation facilities, the existing transport systems, land use, and street layout are known to either discourage or encourage physical activity. In this case, it is prudent to note that people are more active whenever they have easier access to critical destinations such as shops, workplaces, green spaces, and sport and recreational facilities.

On the other hand, disadvantaged members of the overall population and those with low income tend to be less active since they cannot access or afford facilities and programs that foster active living in urban spaces. In addition, 
they are more likely to live in neighborhoods that are prone to more traffic safety and crime concerns. Thus, local plans and strategies should be enacted to promote physical activity for people of all genders and ages irrespective of their living and social circumstances in diverse urban spaces, paying particular attention to vulnerability, deprivation, and equity. Furthermore, it is imperative to create more opportunities for physical activity close to where people live. More activity-friendly, greener, and cleaner environments also need to be developed, and partnershipbased models need to focus on promoting physical activity in diverse settings such as transport systems, healthcare and educational settings, various neighborhoods, and leisure and sport organizations.

In Europe, many car trips need to be replaced by cycling and walking. Bicycle and pedestrian travel can be increased through changes in local-level policies, traffic calming measures, and the development of urban infrastructure such as cycle paths, lanes, and tracks. Notably, more people will cycle and walk when it is convenient and there is a reduction in traffic speed and availability of safer infrastructure such as paths and cycle lanes. Overall, effective partnerships at local levels in different nations are critical to the successful implementation of policies that foster and advance physical exercise. Additionally, efforts to enable and encourage physical activity necessitate the cooperation of the sports, education, social services, public health, transport, housing, and urban planning sectors, as well as the voluntary and private sectors. Furthermore, healthcare is better positioned to take a supportive and leading role in promoting physical activity and reducing sedentary living for all urban residents and to pursue partnerships geared toward enhancing active living within the urban environment.

\section{Conclusions}

The modern way of life imposes rhythms and habits on citizens that move them away from a healthy way of living. Increased working hours and technology deter urban residents from participating in healthy activities such as active leisure time and exercise. As a result, there are high levels of inactivity and a very large percentage of people in urban centers have chronic diseases. These citizens are unable or even unwilling to follow a healthy active lifestyle, in most cases because of the absence of an adequate policy for the outdoor urban environment. These days, the effectiveness of outdoor active leisure or exercise in urban open spaces is globally accepted. It is also well known that the creation of conditions and facilities for active leisure, recreation, and exercise in urban open spaces is the duty of local, regional, or even national authorities through policies that satisfy the needs of residents.

The present study collected data from citizens who exercise during their leisure time in urban open spaces and parks in order to create a convenient environment for exercise through green policies. As citizens' concern about active exercise is becoming more and more significant in the sustainable society, individuals are moving towards more environmentally friendly policies and exercise facilities. It can be considered one more step in collecting more information on urban open spaces to increase physical activity in order to improve quality of life through an urban sustainability setting.

The most important finding of the study was the connectedness of leisure time for physical activities, sports, and exercise with citizens' desire for healthier and environmentally friendly urban open spaces and conditions. The citizens expressed their needs and desires for more comfortable, convenient, and safer exercise routes or active leisure activities in urban open spaces. It is remarkable that the high scores for the existence of an environmentally friendly policy to support exercise and recreation facilities were represented by a mosaic of very different types of citizens with different marital statuses and educational levels and from different age groups. The findings also uncovered citizens' intentions to support environmentally friendly policies through their individual contributions.

These findings pose a challenge to any municipality, region, or national government to react successfully and create an environmental policy that allows citizens to live an active and healthy everyday life. However, due to the small sample size analyzed, the present research results should only be generalized and compared to other regions or countries with caution. A comparative analysis of the needs of active citizens from different regions concerning urban open spaces for the achievement of greening objectives should be included in a future study.

It is imperative to note that citizens' physical exercise time in urban environments results in the creation of corresponding preferences and beliefs towards environmentally friendly policies. Overall, people are more likely to engage in active living when they have the support of co-workers, friends, family, and local governments. Physical environments also provide sustainable opportunities that foster social cohesion in regions, cities, and neighborhoods. As such, society can ensure the welfare of all members, avoid polarization, and minimize existing and future disparities. 


\section{References}

Aguiñaga, S., Ehlers, D. K., Salerno, E. A., Fanning, J., Motl, R. W., \& McAuley, E. (2018). A home-based physical activity program improves depression and anxiety in older adults. Journal of Physical Activity and Health, 15(9), 692-696. Doi: 10.1123/jpah.2017-0390

Andrade, A. C. D. S., Mingoti, S. A., Fernandes, A. P., Andrade, R. G. D., Friche, A. A. D. L., Xavier, C. C., ... Caiaffa, W. T. (2018). Neighborhood-based physical activity differences: Evaluation of the effect of health promotion program. PloS One, 13(2), e0192115. Doi: 10.1371/journal.pone.0192115

Bamberg, J., Hitchings, R., \& Latham, A. (2018). Enriching green exercise research. Landscape and Urban Planning, 178, 270-275. Doi: 10.1016/j.landurbplan.2018.06.005

Biernat, E. \& Buchholtz, S. (2016). The regularities in insufficient leisure-time physical activity in Poland. Environmental Research and Public Health, 13, 798, 1-12. Doi: 10.3390/ijerph13080798

Breda, J., Jakovljevic, J., Rathmes, G., Mendes, R., Fontaine, O., Hollmann, S. \& Galea, G. (2018). Promoting healthenhancing physical activity in Europe: Current state of surveillance, policy development, and implementation. Health Policy, 122(5), 519-527. Doi: 10.1016/j.healthpol.2018.01.015

Camhi, S. M., Troped, P. J., Garvey, M., Hayman, L. L., Must, A., Lichtenstein, A. H., \& Crouter, S. E. (2019). Associations between Walk Score and objective measures of physical activity in urban overweight and obese women. PloS One, 14(3), e0214092. Doi: 10.1371/journal.pone.0214092

Chen, P., Jiao, J., Xu, M., Gao, X., \& Bischak, C. (2018). Promoting active student travel: A longitudinal study. Journal of Transport Geography, 70, 265-274. Doi: 10.1016/j.jtrangeo.2018.06.015

Cheung, C., Talley, K. M., McMahon, S., Schorr, E., \& Wyman, J. F. (2020). Knowledge of physical activity guidelines and its association with physical activity and physical function in older adults. Activities, Adaptation, \& Aging, 44(2), 106-118. Doi: 10.1080/01924788.2019.1591152

Edwards, P. \& Tsouros, A. (2006). Promoting physical activity and active living in urban environments. World Health Organization. Regional Office for Europe. Retrieved July 22, 2021, from https://apps.who.int/iris/handle/10665/326536

Ellaway, A., Macintyre, S., \& Bonnefoy, X. (2005). Graffiti, greenery, and obesity in adults: Secondary analysis of European cross sectional survey. BMJ, 331(7517), 611-612. Doi: 10.1136/bmj.38575.664549.F7

Gladwell, V., Brown, D., Wood, C., Sandercock, G., \& Barton, J. (2013). The great outdoors: How a green exercise environment can benefit all. Extreme Physiology \& Medicine, 2(3), 1-7. Doi: 10.1186/2046-7648-2-3

Godin, G. \& Shephard, R. J. (1997). Godin leisure-time exercise questionnaire. Medicine \& Science in Sports \& Exercise, 29(6), S36-S38.

Hesketh, K. R., Lakshman, R., \& van Sluijs, E. M. (2017). Barriers and facilitators to young children's physical activity and sedentary behavior: A systematic review and synthesis of qualitative literature. Obesity Reviews, 18(9), 987-1017. Doi: $10.1111 /$ obr.12562

Hopkins, M., Gibbons, C., \& King, N. A. (2018). Physical activity for weight loss in obesity. In C. Hankey (Eds.), Advanced Nutrition and Dietetics in Obesity (pp. 212-221). UK: Wiley.

Hu, L., Zhu, L., Xu, Y., Lyu, J., Imm, K., \& Yang, L. (2017). Relationship between air quality and outdoor exercise behavior in China: A novel mobile-based study. International Society of Behavioural Medicine, 24, 520-527. Doi: 10.1007/s12529-017-9647-2

Jin, H., Kwon, Y., Yoo, S., Yim, D., \& Han, S. (2021). Can urban greening using abandoned places promote citizens' wellbeing? Case in Daegu City, South Korea. Urban Forestry \& Urban Greening, 57, 1-11. Doi: 10.1016/j. ufug.2020.126956

Johnson, B. E. \& Shifferd, J. (2016). Who lives where: A comprehensive population taxonomy of cities, suburbs, exurbs, and rural areas in the United States. The Geographical Bulletin, 57(1), 25.

Kabisch, N. \& Kraemer, R. (2020). Physical activity patterns in two differently characterized urban parks under conditions of summer heat. Environmental Science \& Policy, 107, 56-65. Doi: 10.1016/j.envsci.2020.02.008

Kontogianni, E. (2015). The effect of green marketing to participants' behavior in sports tourism \& recreation services. Unpublished doctoral dissertation, University of Thessaly, Trikala, Greece.

Kontogianni, E., Kouthouris, C., \& Zafeiroudi, A. (2014). Environmentally friendly behavior in Greek leisure centres and different participants' characteristics. Journal of Management Research, 6(4), 155-175.

Kontogianni, E., Zafeiroudi, A., \& Kouthouris, C. (2020). Integrating green marketing issues in water sport recreation activities. Journal of Physical Education and Sport Management, 7, 1, 44-54. Doi: 10.15640/jpesm.v7n1a6 
Kostrzewska, M. (2017). Activating public space: How to promote physical activity in an urban environment. In IOP Conference Series: Materials Science and Engineering (Vol. 245, pp. 1-10). Bristol, UK: IOP Publishing. Doi: 10.1088/1757-899X/245/5/052074

Li, F., Zheng, W., Wang, Y., Liang, J., Xie, S., Guo, S., Li, X., \& Yu, C. (2019). Urban green space fragmentation and urbanization: A spatiotemporal perspective. Forests, 10(4), 333. Doi: 10.3390/f10040333

Livy, M. R. \& Klaiber, H. A. (2016). Maintaining public goods: The capitalized value of local park renovations. Land Economics, 92(1), 96-116. Doi: 10.3368/le.95.3.369

Madureira, J., Brancher, E. A., Costa, C., de Pinho, R. A., \& Teixeira, J. P. (2019). Cardio-respiratory health effects of exposure to traffic-related air pollutants while exercising outdoors: A systematic review. Environmental Research, 178, 1-10. Doi: 10.1016/j.envres.2019.108647

Mayo Clinic Staff. (2017, September 27). Depression and Anxiety: Exercise Eases Symptoms. Retrieved May 5, 2020, from https://www.mayoclinic.org/diseases-conditions/depression/in-depth/depression-and-exercise/art-20046495

Mengesha, M. M., Roba, H. S., Ayele, B. H., \& Beyene, A. S. (2019). Level of physical activity among urban adults and the socio-demographic correlates: A population-based cross-sectional study using the global physical activity questionnaire. BMC Public Health, 19(1), 1160. Doi: 10.1186/s12889-019-7465-y

Moholdt, T., Lavie, C. J., \& Nauman, J. (2018). Sustained physical activity, not weight loss, associated with improved survival in coronary heart disease. Journal of the American College of Cardiology, 71(10), 1094-1101. Doi: 10.1016/j. jacc.2018.01.011

Panter, J., Guell, C., Prins, R., \& Ogilvie, D. (2017). Physical activity and the environment: Conceptual review and framework for intervention research. International Journal of Behavioral Nutrition and Physical Activity, 14(1), 156. Doi: 10.1186/s12966-017-0610-Z

Panter, J., Heinen, E., Mackett, R., \& Ogilvie, D. (2016). Impact of new transport infrastructure on walking, cycling, and physical activity. American Journal of Preventive Medicine, 50(2), e45-e53. Doi: 10.1016/j.amepre.2015.09.021

Pawlikowska-Piechotkaanna, A. \& Sawicka, K. (2013). Sport and recreation grounds: Urban society expectations. Physical Culture and Sport. Studies and Research, 57(1), 33-43. Doi: 10.2478/pcssr-2013-0006

Pyky, R., Neuvonen, M., Kangas, K., Ojala, A., Lanki, T., Borodulin, K., \& Tyrvainen, L. (2019). Individual and environmental factors associated with green exercise in urban and suburban areas. Health \& Place, 55, 20-28. Doi: 10.1016/j. healthplace.2018.11.001

Rech, C. R., Reis, R. S., Hino, A. A. F., \& Hallal, P. C. (2014). Personal, social and environmental correlates of physical activity in adults from Curitiba, Brazil. Preventive Medicine, 58, 53-57. Doi: 10.1016/j.ypmed.2013.10.023

Saito, Y., Oguma, Y., Tanaka, A., Kamada, M., Inoue, S., Inaji, J., ... Narumi, Y. (2018). Community-wide physical activity intervention based on the Japanese physical activity guidelines for adults: A non-randomized controlled trial. Preventive Medicine, 107, 61-68. Doi: 10.1016/j.ypmed.2017.11.008

Sallis, J. F., Cerin, E., Conway, T. L., Adams, M. A., Frank, L. D., Pratt, M., \& Davey, R. (2016). Physical activity in relation to urban environments in 14 cities worldwide: A cross-sectional study. The Lancet, 387(10034), 2207-2217. Doi: 10.1016/S0140-6736(15)01284-2

Schipperijn, J., Bentsen, P., Troelsen, J., Toftager, M., \& Stigsdotter, U. K. (2013). Associations between physical activity and characteristics of urban green space. Urban Forestry \& Urban Greening, 12(1), 109-116. Doi: 10.1016/j. ufug.2012.12.002

Schüller, I. \& Demetriou, Y. (2018). Physical activity interventions promoting social competence at school: A systematic review. Educational Research Review, 25, 39-55. Doi: 10.1016/j.edurev.2018.09.001

Stanley, B. W., Stark, B. L., Johnston, K. L., \& Smith, M. E. (2013). Urban open spaces in historical perspective: A transdisciplinary typology and analysis. Urban Geography, 33(8), 1089-1117. Doi: 10.2747/0272-3638.33.8.1089

Sugiyama, T., Howard, N. J., Paquet, C., Coffee, N. T., Taylor, A. W., \& Daniel, M. (2015). Do relationships between environmental attributes and recreational walking vary according to area-level socioeconomic status? Journal of Urban Health: Bulletin of the New York Academy of Medicine, 92(2), 253-264. Doi: 10.1007/s11524-014-9932-1

Tan, C. L. Y., Chang, C., Nghiem, L. T. P., Zhang, Y., Oh, R. R. Y., Shanahan, D. F., Lin, B. B., Gaston, K. J., Fuller, R. A., \& Carrasco, L. R. (2021). The right mix: Residential urban green-blue space combinations are correlated with physical exercise in a tropical city-state. Urban Forestry \& Urban Greening, 57, 1-12. Doi: 10.1016/j.ufug.2020.126947

Tan, S., Li, Y., Song, Y., Luo, X., Zhou, M., Zhang, L., \& Kuang, B. (2017). Influence factors on settlement intention for floating population in urban area: A China study. Quality \& Quantity, 51(1), 147-176. Doi: 10.1007/s11135-0150299-5

Tuyckom, C. V. (2011). Macro-environmental factors associated with leisure-time physical activity: A cross-national analysis of EU countries. Scandinavian Journal of Public Health, 39, 419-426. Doi: 10.1177/1403494810396553 
Wagner, A. L., Keusch, F., Yan, T., \& Clarke, P. J. (2019). The impact of weather on summer and winter exercise behaviors. Journal of Sport and Health Sciences, 8, 39-45. Doi: 10.1016/j.jshs.2016.07.007

World Health Organization (WHO). (2020). Non communicable diseases and their risk factors. How active are we? Retrieved December 12, 2020, from https://www.who.int/ncds/prevention/physical-activity/inactivity-global-healthproblem/en/

Winters, M., Buehler, R., \& Götschi, T. (2017). Policies to promote active travel: Evidence from reviews of the literature. Current Environmental Health Reports, 4(3), 278-285. Doi: 10.1007/s40572-017-0148-x

Zafeiroudi, A. (2020). Enhancing adolescents' environmental responsibility through outdoor recreation activities. $A c a-$ demic Journal of Interdisciplinary Studies, 9(6), 43-55. Doi: 10.36941/ajis-2020-0110

Zafeiroudi, A. \& Hatzigeorgiadis, A. (2014a). The effects of an outdoor pursuit's intervention program on adolescents' environmental beliefs. International Journal on Advances in Education Research, 1(3), 106-118.

Zafeiroudi, A. \& Hatzigeorgiadis, A. (2014b). Validation of the Greek version of the responsible environmental behavior scale and relationships with participation in outdoor activities. International Journal of Sport Management, Recreation \& Tourism, 13, 20-37. Doi: 10.5199/ijsmart-1791-874X-13b

Zhang, C., Cao, X., \& Ramaswami, A. (2016). A novel analysis of consumption-based carbon footprints in China: Unpacking the effects of urban settlement and rural-to-urban migration. Global Environmental Change, 39, $285-293$. Doi: 10.1016/j.gloenvcha.2016.06.003

Zhou, X. \& Wang, Y. (2011). Spatial-temporal dynamics of urban green space in response to rapid urbanization and greening policies. Landscape and Urban Planning, 100(3), 268-277. Doi: 10.1016/j.landurbplan.2010.12.013

This is Open Access article distributed under the terms of CC-BY-NC-ND 4.0 International License. 